\title{
Determination of the Real Dotation and Forecast of the Potable Water System in the Huancavelica City, Peru
}

Iván Ayala Bizarro, Ivette Contreras Espinoza, Cristel Aguirre Vera, Marco López Barrantes, Jorge Ortega Vargas, Abdon Olivera Quintanilla, Hugo Lujan Jeri and Eleuterio Alcántara Espinoza

Department of Civil Engineering, National University of Huancavelica, Huancavelica 09001, Peru

\begin{abstract}
The research entitled, "Determination of the Real Dotation and Forecast of the Potable Water System in the Huancavelica city-Peru", has as objective to determine and analyze the actual endowment and prognosis of the drinking water system in the city of Huancavelica. The city of Huancavelica has a population of approximately 50,000.00 inhabitants and 10,680.00 users of drinking water and sewerage according to the source Companies Providing This Service, the same one that is located in the western chain and central saw range of Perú and belongs to a cold climate. The sample was extracted through Companies Providing This Service EMAPA Huancavelica SA (Anonymous Society), which corresponds to 1,296 data from the consumption of water in cubic meters of each dwelling located in the various categories of each sector. The results obtained from the research indicate that the category that consumed more water during the period 2004-2018 was the domestic category, the same one that had an average of 1,152,123 cubic meters, this is due to the population growth of each year. On the other side, the category that consumed the least water was the social category, the average consumption of which was $11,903.47$ cubic meters. In addition, the greatest variability in water consumption is in the state category, the total variation being equal to $21.6 \%$. In the Huancavelica city, water consumption has a growing trend and to predict the volume of drinking water consumption by 2030, water consumption was transformed by first differences, using the ARIMA (Autoregressive Integrated Moving Average) model for total consumption model (0-1-1) (2-0-0)-12 and for the domestic consumption the ARIMA model (0-1-2) (0-0-2)-12. On the other hand, water consumption was analyzed on a monthly basis in which there is greater variability for the months June-6 and December-12. It was taken into account for the calculation of the endowment the domestic consumption, having values ranging from $6.45 \mathrm{~L} /$ inhab/day until 1,460 L/inhab/day, which reflects a considerable variation to consider. The average value in the spring station is $109.44 \mathrm{~L} /$ inhab/day, in the summer station it is $116.93 \mathrm{~L} / \mathrm{inh}$ ab/day, in the autumn station it is $117.17 \mathrm{~L} /$ inhab/day and in the winter station it is $108.48 \mathrm{~L} /$ inhab/day. Also, the average minimum endowment equal to $7.66 \mathrm{~L} /$ inhab/day was obtained, the average maximum endowment is of $569.03 \mathrm{~L} /$ inhab/day and the actual endowment 113.01 L/inhab/day. Finally, it is concluded that the estimated average actual endowment for the Huancavelica city, that is to say, 113.01 L/inhab/day, is much less than that indicated in the Norma OS.100 of the Basic Considerations of Sanitary Infrastructure Design of the RNE (Reglamento Nacional de Edificaciones), the same one that mentions the endowment equal to $180 \mathrm{~L} /$ inhab/day for cold climates, which means a reduction of costs in the dimensioning of hydraulic structures and sanitation and drinking water works.
\end{abstract}

Key words: Drinking water, real consumption, critical demand, forecasting drinking water.

\section{Introduction}

The city of Huancavelica, is located in the central zone of Perú, or also known as the andean trapeze. It is characterized by its rugged geography and has an altitude of 3,660 m.s.n.m. Huancavelica city is located on the Suni or Jalca altitude floor and is characterized

Corresponding author: Iván Ayala Bizarro, master, research field: hydrological and hydraulic modeling to prevent flooding and risk analysis. by having a cold climate with a minimum temperature between 2 and $10{ }^{\circ} \mathrm{C}$ and maximum temperature above $20^{\circ} \mathrm{C}$.

The Huancavelica city has approximately 50,000 inhabitants and 10,680 active users who make $73.26 \%$ who consume drinking water.

In the international context, the actual consumption of drinking water is unknown, one of the cases is from residential users in the city of Bogotá, Colombia, where Companies Providing this Service are unaware 
of the way users demand water service and net flow delivered. The endowment data are obtained from Colombian standards (RAS 2000 and NTC 1500), being these data that they use for the dimensioning of the hydraulic structures thus generating the sub or oversizing of these, because it is information that does not come close to reality, which leads to unnecessary budget investments.

Garzón [1] concludes that the average value of the endowment that was obtained $125.24 \mathrm{~L} /$ inhab/day is an acceptable value; it also mentions that the value recommended by the RAS 2000 Standard, which mentions $140 \mathrm{~L} / \mathrm{inhab} /$ day, is not the most suitable for most of the city of Bogotá.

Condor and Asqui [2] obtained the coefficient of daily variation by dividing the endowment of the day with the highest consumption and the average endowment, in which it indicates that the maximum endowment obtained is $154.34 \%$ of the average endowment.

According to Zambrano [3], the endowment is the demand of water of a population to cover their needs, is obtained through a study in which the needs of the plaintiffs are: quench thirst, wash clothes, among others, that is, the amount of water assigned to each inhabitant and that includes the consumption of all services in one day, considering losses. It also mentions that the recommended and most used coefficient is $130 \%$ of the annual average daily consumption.

Castillo [4], concludes that the value of the endowment used in the designs of drinking water systems $220 \mathrm{~L} /$ inhab/day is high compared to the estimated endowment, therefore, drinking water networks would be oversized because they were designed with values that double the estimated endowment through real records and statistical calculations.

The results obtained by Wilson [5] were new coefficients of variation in hourly and daily demand which are adjusted more efficiently to the daily consumption of the population.
For the preparation of investment projects, estimated endowment values are taken in the guidelines issued by the Ministry of Housing of Peru, RNE OS.100, resulting in the development of poorly formulated technical files, because the standards do not conform to reality and in some cases lead to very expensive projects of hydraulic structures $[6,7]$.

Currently in the Huancavelica city there are no real endowments of human consumption making use of an endowment value of $180 \mathrm{~L} /$ inhab/day.

\section{Material and Methods}

The annual average daily consumption is defined as, the result of an estimate of the average consumption per person for the future population of the design period, expressed in liters per second and is determined with the following equation:

$$
Q_{m}=\frac{\operatorname{Hxdotación}(d)}{86,400}
$$

Where:

$Q_{m}$ : Average daily consumption (L/s)

$H$ : Number of inhabitants

$d$ : Dotation (L/inhab/day)

On the other hand, a series of time was used to forecast [8] water consumption, where observations over time are denoted by:

$Y_{1}+Y_{2}+Y_{3}+\cdots+Y_{K}$; Where $k$ is the number of observations.

According to Gonzalo [9] and Calvo [10], he mentions that a series can be non-stationary and stationary, the latter being the one that must be constant in the mean and in the variance. [11] All-time series must comply with the process of identification, estimation, validation and prediction, estimation, validation and prediction.

\section{Models ARIMA Box-Jenkins Methodology}

An ARIMA model $(0, d, 0)$ is a time series that becomes a purely random process after differentiation $d$ times $[12,13]$.

The model Box-Jenkins ARIMA is presented by the following equation: 


$$
\begin{aligned}
& Y_{t}=\emptyset_{0}+\emptyset_{1} y_{t-1}+L+\emptyset_{p} y_{t-p}+ \\
& a_{t}-\emptyset_{1} a_{t-1}-L-\emptyset_{q} a_{t-q}
\end{aligned}
$$

\section{Autoregressive model (AR)}

The finite autoregressive model of order "p", AR (p) is an approximation natural to the general linear model:

$$
\begin{aligned}
& A R(p)=X_{t}= \\
& a_{t}-\Phi_{1} X_{t-1}-\Phi_{2} X_{t-2}-\Phi_{3} X_{t-3}-\cdots-\Phi_{p} X_{t-p}
\end{aligned}
$$

Moving averages processes: MA (p)

$$
\begin{gathered}
M A(q)=X_{t}= \\
a_{t}-v_{1} a_{t-1}-v_{2} a_{t-2}-\cdots-v_{q} a_{t-q}
\end{gathered}
$$

\section{Procedure for Selecting the Best Model}

\subsection{Total Water Forecast}

To choose the best forecast model, the model must go through phases of stationarity, normality and Akaike information criteria.

Try stationarity using Dickey-fuller.

\section{Basic definition:}

\section{Akaike criterion:}

$$
\begin{gathered}
H_{1}: y_{t}=a_{1} y_{t-1}+\varepsilon_{t} \\
H_{0}: y_{t}=y_{t-1}+\varepsilon_{t}
\end{gathered}
$$

Normality test:

$$
\operatorname{CIA}(k)=-2 \ln \mathcal{L}[\widehat{\theta}(k)]+2 k
$$

$$
\begin{aligned}
& H_{\mathbf{1}}: \boldsymbol{p}<0.05 \\
& \boldsymbol{H}_{\mathbf{0}}: \boldsymbol{p}>0.05
\end{aligned}
$$

\section{Applications}

In Fig.1, as it can be observed in the graph, the greatest variability in water consumption is in the state category, followed by the social, industrial, commercial and domestic category. At a total level, there is a variation of $21.6 \%$.

In Fig. 2, it shows the behavior of water consumption in the domestic category is observed where it shows a variant behavior. It means, it is not constant either on average or in variation, in addition, you see a growing trend, that is, over the years the water consumption (volume) in this city is getting higher. In addition, the series does not show stationarity.

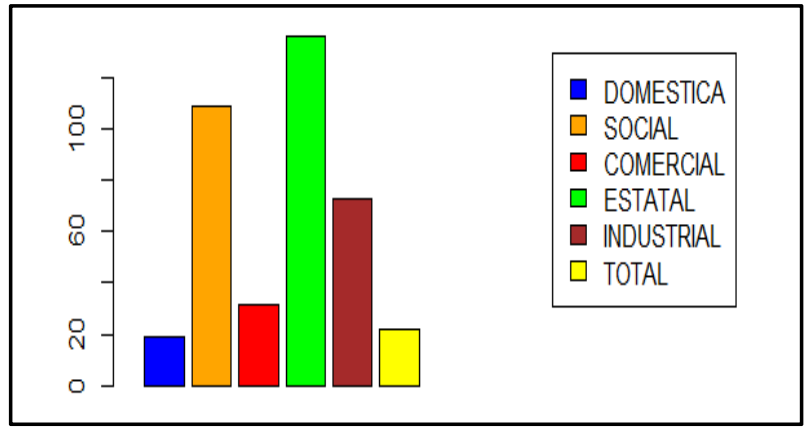

Fig. 1 Coefficient of variation for the consumption of total drinking water or by categories in the Huancavelica city period 2004-2018.

Source: EMAPA Huancavelica SA (2004-2018).

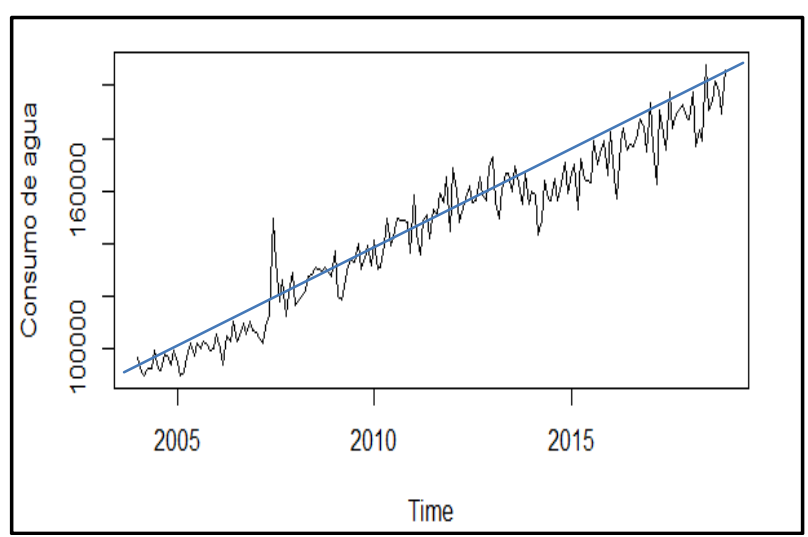

Fig. 2 Behavior of the series of total water consumption in the city of Huancavelica period 2004-2018.

Source: EMAPA Huancavelica SA (2004-2018).

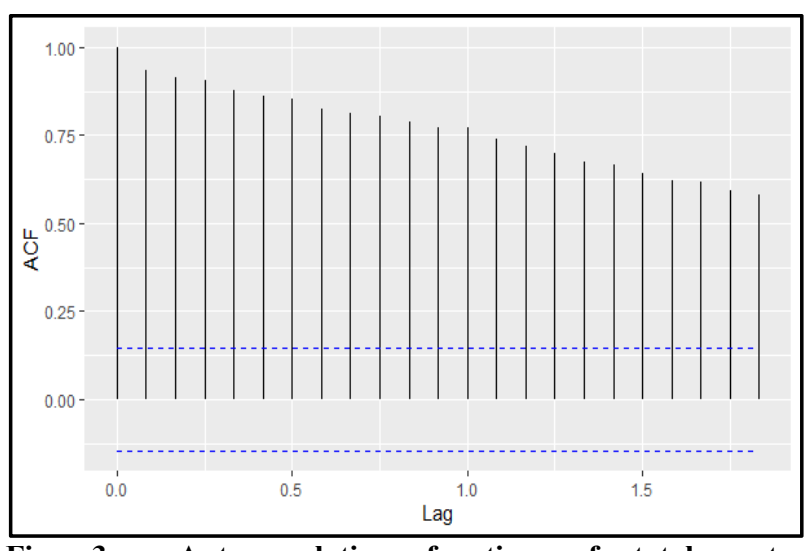

Fig. 3 Autocorrelation function of total water consumption in the Huancavelica city period 2004-2014. Source: EMAPA Huancavelica SA (2004-2018).

In Fig. 3, by a confidence of $95 \%$, it is appreciated how the series is not stationary since the value of the autocorrelation function does not decline exponentially as traits increase; that is to say it has a slow decay. Therefore, first differences will have to be 


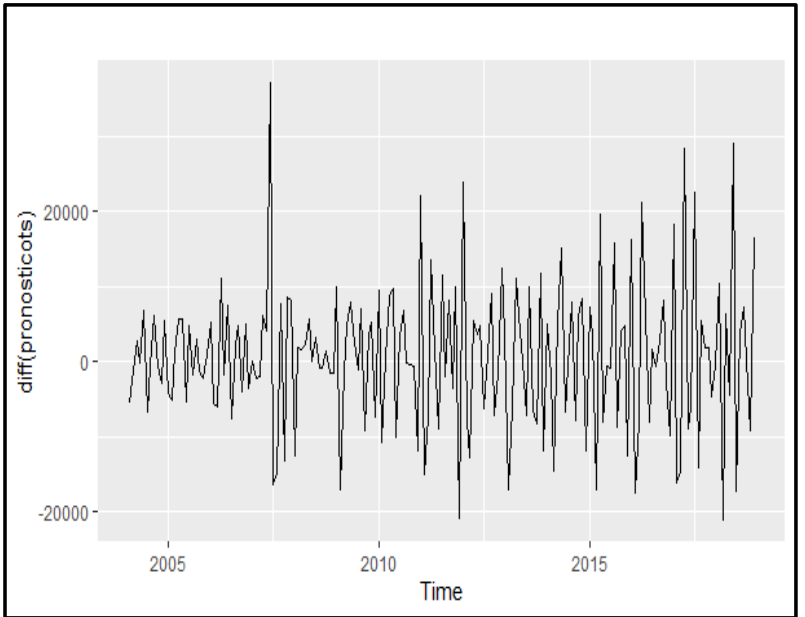

Fig. 4 Series of the total water consumption in the city of Huancavelica for the period 2004-2014 in first differences.

made to the water consumption data. At the same time, using the function that calculates the number of regular differentiations (ndiffs) it was estimated that the series is stationary, and using the function that calculates the number of seasonal differentiations (nsdiffs), indicated that the series is not seasonal. Therefore, transformation will be applied to the series.

In Fig. 4, shows the series of water consumption in first differences, with the purpose of turning the series into stationary. With a $95 \%$ of confidence, it is observed that the series in first differences does not trend, and it shows signs of being constant in average and in variance.

\section{Dickey-Fuller Test}

This test allowed us to determine if there are unit roots in the series:

$$
\Delta y_{t}=\alpha+y y_{t-1}+\sum_{i=2}^{p} \beta \Delta y_{t-i+1}+\varepsilon_{t}
$$

$\mathrm{H}_{0}$ : The series presents almost a unit root (not stacionary).

$\mathrm{H}_{1}$ : The series does not present unit roots (stacionary).

P-value: 4.083e-09.

As it can be observed the Dickey-Fuller test with a 95\% confidence level rejects the null hypothesis and accepts the alternative, therefore, it is claimed that the series is stationary applying first differences.

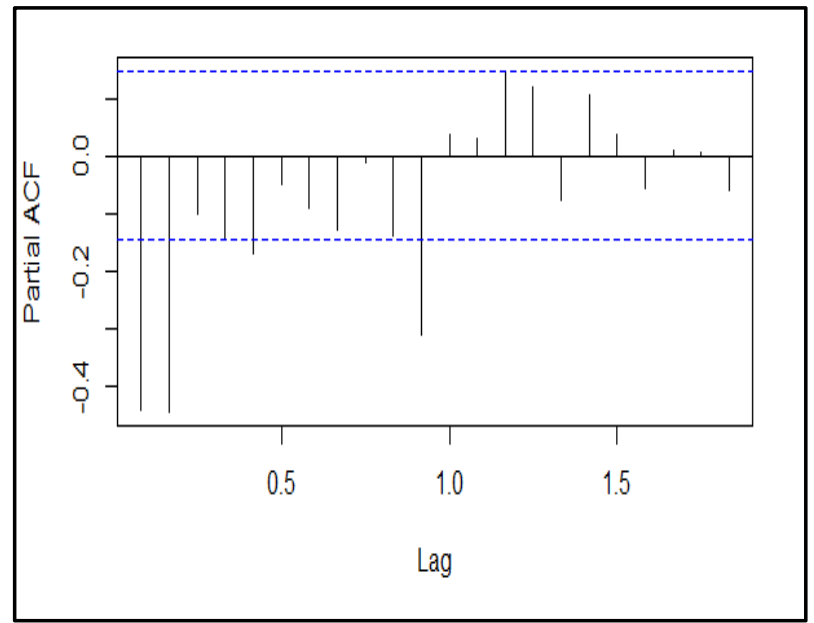

Fig. 5 Partial autocorrelation function of total water consumption in the city of Huancavelica period 2004-2014 in first differences.

In Fig. 5, it is observed that the model has exponential decay, and it must have part of the moving average. The partial autocorrelation function suggests an ARIMA model $(0,1,1)(2,0,0)$ which will allow us to describe the behavior of the drinking water consumption series.

In Fig. 6, the forecast of water consumption is observed where the forecast is observed until the year 2030, the data were projected in order to know the amount in volume of water consumption for the next 10 years.

Table 1, with a $95 \%$ confidence level, shows the forecast of water consumption until 2030, that is, the Arima model (0-1-1) (2-0-0)-12. It allowed us to forecast the water consumption of the Huancavelica city for the next 10 years. The band constructed by confidence interval limits is presented, with a lower

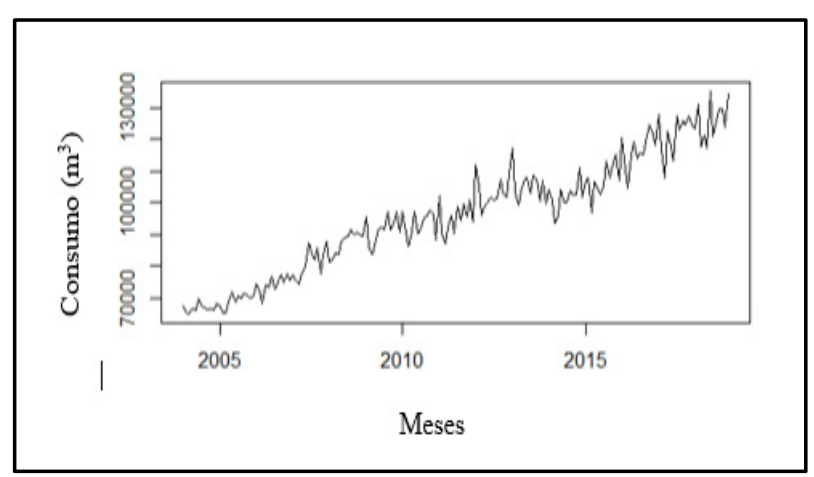

Fig. 6 Forecast of total water consumption in the Huancavelica city, Perú. 
Table 1 Predicted values for water consumption in the Huancavelica city by 2030.

\begin{tabular}{lllll}
\hline & Point & Forecast & Lo 95 & Hi 95 \\
\hline Jan. & 2030 & $208,508.5$ & $137,103.9$ & $279,913.1$ \\
Feb. & 2030 & 208,524 & $136,800.8$ & $280,247.2$ \\
Mar. & 2030 & $208,459.4$ & 136,419 & $280,499.8$ \\
Apr. & 2030 & $208,495.5$ & $136,139.3$ & $280,851.7$ \\
May & 2030 & $208,477.9$ & $135,807.2$ & $281,148.5$ \\
Jun. & 2030 & $208,548.4$ & $135,564.7$ & $281,532.1$ \\
Jul. & 2030 & $208,519.3$ & $135,223.8$ & $281,814.8$ \\
Aug. & 2030 & $208,519.5$ & $134,913.6$ & $282,125.5$ \\
Sep. & 2030 & $208,541.8$ & $134,626.7$ & $282,456.8$ \\
Oct. & 2030 & $208,534.8$ & $134,311.9$ & $282,757.7$ \\
Nov. & 2030 & $208,512.5$ & $133,983.1$ & $283,041.9$ \\
Dec. & 2030 & $208,551.5$ & $133,716.8$ & $283,386.3$ \\
\hline
\end{tabular}

Source: Water projection in Huancavelica.

(Lo 95) and higher (Hi 95) limit of the 95\% confidence interval for the year 2030.

Water Consumption for the Domestic Category

Fig. 7 shows the behavior of the domestic water consumption series in the Huancavelica city, where it is shown that its behavior is increasing, therefore, it is expected that it will not be stationary (not constant either on average or in variance).

In Fig. 8, it is observed that each of the lags has slow decay, therefore, it is another reason to say that the series is non-stationary, and that it will have to be differentiated in order to work with the ARIMA models.

As seen in Fig. 9, the series was transformed into first differences in order to make it stationary. Therefore, it is noted that it no longer has an increasing form but that its values already embroider the average.

In Fig. 10, the simple autocorrelation function is shown where it shows that the model could be an ARIMA (0-1-2) (0-0-2). But first of all, we will proceed to perform the Dickey-Fuller test again to test the stationarity in the series.

ARIMA model (0-1-2) (0-0-2)-12

\begin{tabular}{lll}
\hline AIC & AICc & BIC \\
$3,494.9$ & $3,495.39$ & $3,514.02$ \\
\hline
\end{tabular}

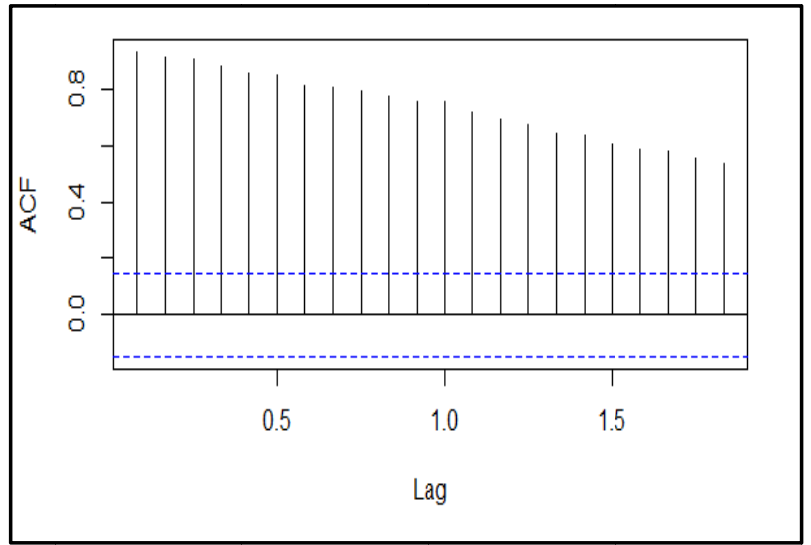

Fig. 7 Sequence chart of domestic water consumption in the Huancavelica city.

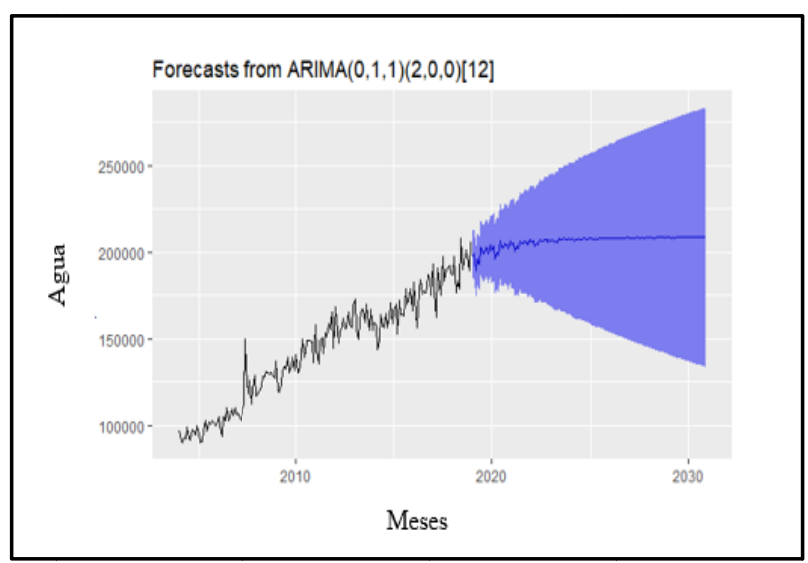

Fig. 8 Autocorrelation function of domestic water consumption in the Huancavelica city.

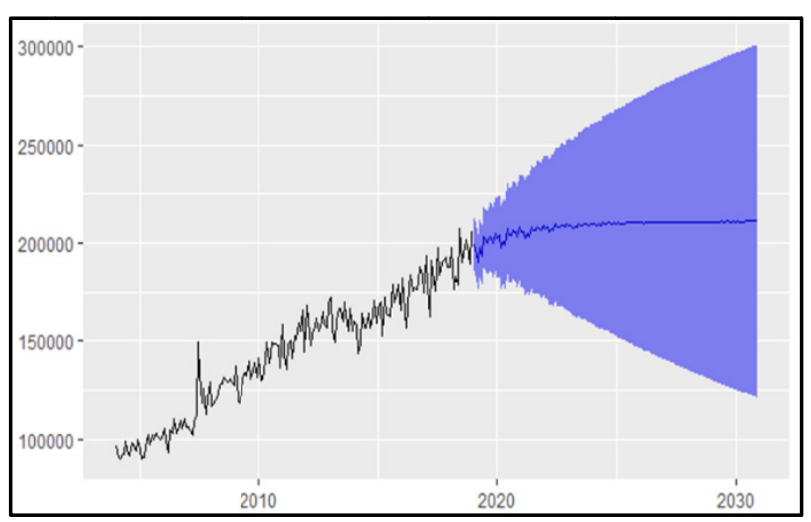

Fig. 9 Sequence chart of domestic water consumption in the Huancavelica city in first differences.

The table shows that the AIC (Akaike Information Criterion) is equal to 3,494.9, while the BIC (Bayesian Information Criterion) showed a value equal to 3,514.02; it means, the ARIMA model (0-1-2) (0-0-2)-12, was the one that best predicts the consumption of domestic water in the Huancavelica city, Peru. 


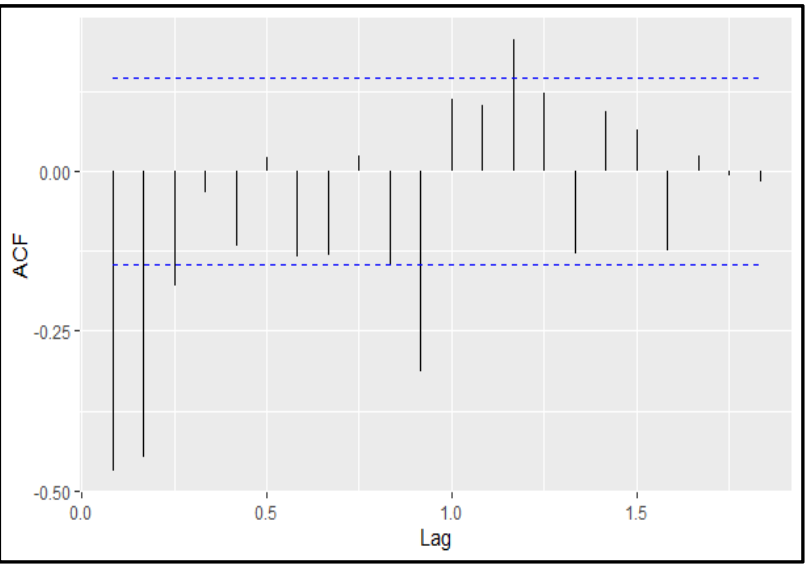

Fig. 10 Simple autocorrelation function of domestic water consumption in the Huancavelica city in first differences.

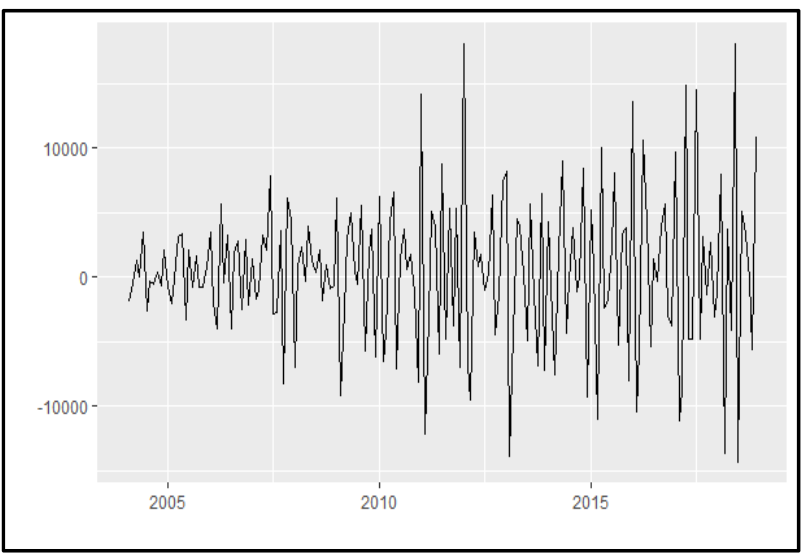

Fig. 11 Forecast of water consumption in the domestic category in the Huancavelica city with ARIMA Model (0-1-2) (0-0-2)-12.

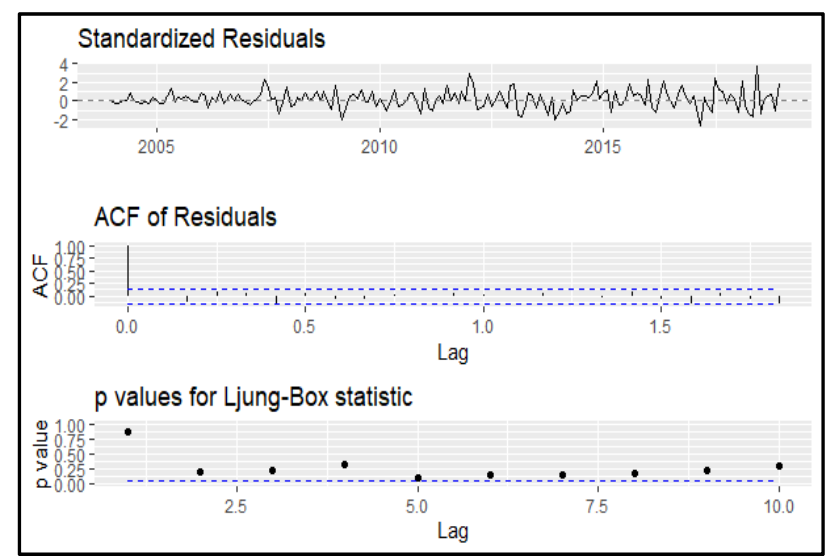

Fig. 12 Residuals of domestic water consumption in the Huancavelica city with ARIMA Model (0-1-2) (0-0-2)-12.

In Fig. 11, the predicted values are shown where the values are evidenced until 2030, indicating in blue the forecast made according to the ARIMA model (0-1-2) (0-0-2)-12.
Normality of residuals

\begin{tabular}{ll}
\hline Test of Jarque-Bera & Shapiro test \\
\hline 0.87 & 0.172 \\
\hline
\end{tabular}

Table 2 Predicted values for water consumption in the domestic category.

\begin{tabular}{lllll}
\hline & Point & Forecast & Lo 95 & Hi 95 \\
\hline January & 2030 & $211,036.3$ & $125,482.7$ & $296,589.8$ \\
February & 2030 & $211,043.3$ & $125,090.9$ & $296,995.7$ \\
March & 2030 & $210,968.1$ & $124,618.9$ & $297,317.3$ \\
April & 2030 & $211,019.6$ & $124,273.9$ & $297,765.2$ \\
May & 2030 & $210,991.1$ & $123,851.1$ & $298,131.1$ \\
June & 2030 & $211,089.1$ & $123,556.8$ & $298,621.4$ \\
July & 2030 & $211,051.2$ & $123,128.2$ & $298,974.2$ \\
August & 2030 & $211,050.1$ & $122,738.1$ & 299,362 \\
September & 2030 & $211,081.2$ & $122,381.9$ & $299,780.4$ \\
October & 2030 & $211,071.8$ & 121,987 & $300,156.5$ \\
November & 2030 & $211,041.1$ & $121,572.4$ & $300,509.7$ \\
December & 2030 & $211,094.6$ & $121,243.7$ & $300,945.6$ \\
\hline
\end{tabular}

Source: Water Projection Huancavelica.

Fig. 12 shows the residuals obtained in the ARIMA model (0-1-2) (0-0-2)-12, where normality of the data is shown, therefore, it can be constant on average and in variance.

As shown in the table, the Jarque-Bera and Shapiro-Wilk test show that the residues behave normally, therefore, the model is the best for forecasting domestic water consumption.

Table 2, it shows the predicted values until the year 2030 , indicate that the consumption of water, with the passing of the years will follow a growing positive trend, since one of the pillars will be based on the population increase in this city. The band constructed by the limits of the confidence interval for the domestic category is presented, with a lower (Lo 95) and higher (Hi 95) limit of the 95\% confidence interval for the year 2030.

Table 3 shows the supply (liters per inhabitant per day) of each month, in period August 2018 to July 2019, where it is observed that, in 2019, December, an inhabitant will consume on average 113.98 liters of water.

According to Table 4, it shows the supply (liters per inhabitant per day) of each season, where it is 
Table 3 Supply (liters per inhabitant per day) of each month, Period August 2018 to July 2019.

\begin{tabular}{llll}
\hline & Minimum & Maximum & Average \\
\hline January & 6.45 & 703.23 & 120.67 \\
February & 7.14 & 721.43 & 138.43 \\
March & 6.45 & 400.00 & 91.70 \\
April & 6.67 & 1460.00 & 115.25 \\
May & 6.45 & 496.77 & 115.41 \\
June & 6.67 & 600.00 & 120.86 \\
July & 6.45 & 503.23 & 109.74 \\
August & 6.45 & 458.06 & 111.11 \\
September & 6.67 & 413.33 & 107.47 \\
October & 12.90 & 296.77 & 106.87 \\
November & 6.67 & 440.00 & 107.47 \\
December & 6.45 & 541.94 & 113.98 \\
\hline
\end{tabular}

Source: EMAPA Huancavelica SA. Huancavelica, Perú, 2019.

Table 4 Supply (liters per inhabitant per day) of each season of the year, in period August 2018 to July 2019.

\begin{tabular}{lllll}
\hline & Spring & Summer & Fall & Winter \\
\hline Min. & 8.67 & 6.68 & 6.59 & 8.67 \\
Max & 426.24 & 608.22 & 852.26 & 389.39 \\
Pro & 109.44 & 116.93 & 117.17 & 108.48 \\
\hline
\end{tabular}

Source: EMAPA Huancavelica SA. Huancavelica, Perú, 2019.

Table 5 Real supply (liters per inhabitant per day) of Huancavelica city, Peru, in period August 2018 to July 2019.

\begin{tabular}{lll}
\hline & \multicolumn{2}{l}{ Huancavelica } \\
\hline Minimum & 7.66 & L/inhab/day \\
Maximum & 569.03 & L/inhab/day \\
Average & 113.01 & L/inhab/day \\
\hline
\end{tabular}

Source: EMAPA Huancavelica SA, Peru, 2019.

observed that an inhabitant tends to consume more in the fall season $(852.26 \mathrm{~L})$.

According to Table 5, the average supply is shown in (liters per inhabitant per day) for the city of Huancavelica, Peru that is 113.01 liters per inhabitant per day.

\section{Conclusions}

In the investigation it has been obtained, that the highest consumption was the domestic category, with an average of 1,152,123 cubic meters, during the period 2004-2018. On the other hand, the category that consumed the least was the social category, whose average is $11,903.47$ cubic meters. Further, the greatest variability in water consumption is in the state category, being the total variation of $21.6 \%$.

It has been concluded that water consumption has a positive trend. Transformed by first differences, an ARIMA model equal to (0-1-1) (2-0-0)-12 is obtained for the total and for domestic consumption an ARIMA model (0-1-2) (0-0-2)-12. On the other hand, if analyzed monthly, greater variability can be observed for the months June - 6 and December - 12 .

Likewise, water consumption records were projected until 2030 years with a $95 \%$ confidence level. The ARIMA model used is (0-1-1) (2-0-0)-12, which allowed us to forecast the water consumption of the Huancavelica city for the next 10 years.

Also, allocations have been observed from 6.45 $\mathrm{L} /$ inhab/day to $1,460 \mathrm{~L} /$ inhab/day, which reflects a considerable variation that must be taken into account. The average value in the spring season is 109.44 $\mathrm{L} /$ inhab/day, in the summer season it is 116.93 $\mathrm{L} /$ inhab/day, in the autumn season it is 117.17 $\mathrm{L} / \mathrm{inhab} /$ day and finally in the winter season it is 108.48 L/inhab/day.

Finally, the values of the endowment of the Huancavelica city were obtained, in which we have that the average minimum endowment was 7.66 L/inhab/day, the average maximum endowment is $569.03 \mathrm{~L} /$ inhab/day and the real endowment of 113.01 L/inhab/day.

\section{References}

[1] Garzón, A., and Ortiz, R. 2014. "Determination of Actual Consumption of Drinking Water, for Residential Users of the City of Bogotá." Bogotá Colombia.

[2] Condori, J., and Asqui, C. 2019. "Water Endowment Evaluation for the Project: Improvement of Water and Sanitation Services in the Kunurama Community of the Santa Rosa-Melgar-Puno District, Puno, Perú.” Retrieved on March 2, 2019.

[3] Zambrano, M. 2015. "Water Endowment in Educational Centers in the City of Guayaquil. Comparison with National Standards of Other Countries." Guayaquil, Ecuador. Retrieved on February 24, 2019.

[4] Castillo, L., \& Malaver, C. 2011. Estimation of the 


\section{Huancavelica City, Peru}

Drinking Water Endowment in the A. H. Villa María Enace of Nuevo Chimbote, applying Statistical Methods for Optimization purposes. New Chimbote, Perú. Retrieved on March 2, 2019.

[5] Wilson, G. N. A. 2016. "Determination of the Coefficient of Variation of the Daily Demand and Drinking Water Schedule of the City of Cusco." Cusco, Perú.

[6] Aguirre, A. 2019. "Determination of Water Endowment 2." Recovered on March 1, 2019.

[7] Agüero, P. 2019. "Drinking Water 3." Retrieved on March 24, 2019.

[8] Villareal, F. 2008. Introduction to Forecast Models. Bahía Blanca, Argentina: National University of the South.
[9] Gonzalo, R. 2008. "Series of Time." Research Work, University of Chile, Chile. Obtained from November 14, 2008

[10] Calvo, J. 2019. "Supply of Drinking Water and Sanitation of Urban Wastewater in Spain.” Retrieved on March 2, 2019.

[11] Rosales, R. Econometrics. Bogotá: University of the Andes.

[12] Casimiro, G., and Pilar, M. 2009. Time Series Analysis: ARIMA Models. Lejona: University of the Basque Country.

[13] Gordon, C. 2019. "Real Endowment of Drinking Water in Housing Complexes in the City of Quito, Northern Sector Carcelén, Quito.” Retrieved on March 2, 2019. 